\title{
Fisetin disposition and metabolism in mice: Identification of geraldol as an
}

\section{active metabolite}

Yasmine S. Touil, ${ }^{1}{ }^{* a}$ Nicolas Auzeil, ${ }^{2}{ }^{*}$ François Boulinguez, ${ }^{1}$ Hanane Saighi, ${ }^{1}$ Anne Regazzetti, $^{2}$ Daniel Scherman, ${ }^{1}$ Guy G. Chabot ${ }^{1 * *}$

${ }^{1}$ Université Paris Descartes; Sorbonne Paris Cité; Faculté des Sciences Pharmaceutiques et Biologiques; Institut National de la Santé et de la Recherche Médicale (Inserm U1022); Centre National de la Recherche Scientifique (CNRS UMR8151); Chimie ParisTech; Laboratoire de pharmacologie chimique, génétique \& imagerie, Paris, F-75006 France.

${ }^{2}$ Laboratoire de Chimie et Toxicologie Analytique et Cellulaire (EA 4463); Université Paris Descartes; Faculté des Sciences Pharmaceutiques et Biologiques, Paris, F-75006 France

* Considered as first authors because they contributed equally to this study.

Running title: Fisetin disposition and metabolism in mice

** Corresponding author: Dr. Guy G. Chabot, Chemical, Genetic \& Imaging Pharmacology Laboratory (Inserm U1022 - CNRS UMR8151), Faculté de Pharmacie, Université Paris Descartes, 4 avenue de l'Observatoire, F-75006 Paris, France

Telephone: 33(0)1 5373 9571; Fax: 33(0)1 4326 6918; Email: guy.chabot@parisdescartes.fr

Abbreviations used: bFGF, basic fibroblast growth factor; DMEM, Dulbecco's modified medium; DMSO, dimethylsulfoxide; EAhy 926, immortalized human umbilical vein endothelial cell line; HPLC, high-performance liquid chromatography; $\mathrm{IC}_{50}$, inhibitory concentration for $50 \%$ of cells; LLC, Lewis lung carcinoma cells; MS/MS, tandem mass spectrometry; MTT, 1-(4,5-dimethylthiazol-2-yl)-3,5-diphenyltetrazolium; PBS, phosphate buffered saline.

Keywords: flavonoid, fisetin, pharmacokinetics, metabolism, geraldol, cytotoxicity.

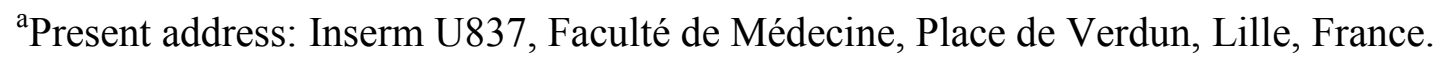




\begin{abstract}
Although the natural flavonoid fisetin $\left(3,3^{\prime}, 4^{\prime}, 7\right.$-tetrahydroxyflavone) has been recently identified as an anticancer agent with antiangiogenic properties in mice, its in vivo pharmacokinetics and metabolism are presently not characterized. Our purpose was to determine the pharmacokinetics and metabolism of fisetin in mice and determine the biological activity of a detected fisetin metabolite. After fisetin administration of an efficacious dose of $223 \mathrm{mg} / \mathrm{kg}$ i.p. in mice, the maximum fisetin concentration reached 2.5 $\mu \mathrm{g} / \mathrm{ml}$ at $15 \mathrm{~min}$ and the plasma concentration declined biphasically with a rapid half-life of $0.09 \mathrm{~h}$ and a terminal half-life of $3.1 \mathrm{~h}$. Three metabolites were detected, one of which was a glucuronide of fisetin (M1), whereas another glucuronide (M2) was a glucuronide of a previously unknown fisetin metabolite (M3). HPLC MS/MS analysis indicated that M3 was a methoxylated metabolite of fisetin (MW=300 Da). The UV spectrum of M3 was identical to that of fisetin and standard 3,4',7-trihydroxy-3'-methoxyflavone (geraldol). In addition, because M3 co-eluted with standard geraldol in 4 different chromatographic ternary gradient conditions, M3 was therefore assigned to geraldol. Of interest, this metabolite was shown to achieve higher concentrations than fisetin in Lewis lung tumors. We also compared the cytotoxic and antiangiogenic activities of fisetin and geraldol in vitro and it was found that the latter was more cytotoxic than the parent compound toward tumor cells, and that it could also inhibit endothelial cells migration and proliferation. In conclusion, these results suggest that fisetin metabolism plays an important role in its in vivo anticancer activities.
\end{abstract}




\section{Introduction}

Among the numerous products available from plants, the flavonoid superfamily plays a central role by their interesting pharmacological properties for several diseases, including cancer prevention and therapy [1-4]. We, and others, have recently identified fisetin $\left(3,3^{\prime}, 4^{\prime}, 7-\right.$ tetrahydroxyflavone, Figure 1), a flavonoid found in several fruits, vegetables, nuts and wine [5;6], as a lead compound possessing biological properties of potential interest in the prevention and/or treatment of cancer in vivo [7-9]. Fisetin possesses antioxidant and antiinflammatory activity $[10 ; 11]$ and was found to be cytotoxic and antiangiogenic in vitro $[12 ; 13]$. Fisetin is cytotoxic to various human cancer cell lines including leukemia (HL60) [14], breast (MCF7) [13], colon (HT29) [15], liver (SK-HEP-1, Caco-2) [15;16], neuroblastoma (SHEP, WAC-2) [13], prostate (LNCaP, PC3) [17], and also to endothelial cells [13]. Fisetin appears to interact with several molecular targets, including cyclindependent kinases [18-20], DNA topoisomerases I and II [21;22], urokinase [23], actin [24], and androgen receptor signaling [7]. It has also recently been found that fisetin induces a forced exit from mitosis by targeting the mitotic spindle checkpoint involving the inhibition of Aurora B activities required for the maintenance of normal spindle checkpoint signaling [25]. In vivo, fisetin has shown antiangiogenic activity after topical application in a rabbit model of corneal neovascularization [26]. After systemic administration in mice, fisetin has shown interesting antitumor activity in several cancer models, including prostate, teratocarcinoma and lung carcinoma [7-9].

Although fisetin has shown activity in vitro and in vivo in mice, there is presently no information concerning the fisetin levels achieved in this preclinical species that could allow in vitro and in vivo comparisons. Moreover, the fisetin molecule bearing 4 hydroxyl substituents, including a catechol on the phenyl B ring, is therefore probably extensively metabolized in vivo. In the present study, at an effective dose of $223 \mathrm{mg} / \mathrm{kg}$ given by the i.p. 
route, we were therefore interested to determine the pharmacokinetics and metabolism of fisetin in vivo in mice.

We report here the pharmacokinetics of fisetin and its main metabolites in mice. In addition to glucuronide conjugates, we identified a 3'-methoxylated metabolite of fisetin (3,4',7-trihydroxy-3'-methoxyflavone or geraldol) as a major metabolite of fisetin. This methoxylated metabolite was found to be more cytotoxic that the parent compound and could also inhibit endothelial cells migration and proliferation. 


\section{Materials and Methods}

\subsection{Chemicals and reagents}

Fisetin (3,3',4',7-tetrahydroxyflavone), kaempferol (3,4',5,7-tetrahydroxyflavone), $\quad \beta$ glucuronidase, dimethylsulfoxide (DMSO), polyethylene glycol 200 (PEG200) were purchased from Sigma-Aldrich (Saint-Quentin Fallavier, France), and geraldol (3,4',7trihydroxy-3'-methoxyflavone) was obtained from Extrasynthese (Genay, France). For HPLC studies, stock solutions of fisetin, kaempferol and geraldol were prepared in methanol and stored at $-20^{\circ} \mathrm{C}$ protected from light. Methanol (HPLC grade) was purchased from Carlo Erba (Val de Reuil, France), glacial acetic acid was from Prolabo (Paris, France), and water was purified using a Milli-Q apparatus from Millipore Corporation. For cell culture, stock solutions of fisetin and geraldol were freshly prepared in DMSO and further diluted in cell culture medium. Matrigel and bFGF were obtained from BD Biosciences (Le Pont de Claix, France). All other chemicals were obtained from commercial sources and were of the highest purity available.

\subsection{Fisetin pharmacokinetics in mice}

Female 8 weeks old C57BL/6J mice (mean body weight 18-22 g), were purchased from Janvier (Le Genest-St-Isle, France). After an overnight fasting period, mice were injected intraperitonelly (i.p.) with fisetin $(223 \mathrm{mg} / \mathrm{kg}$ body weight) dissolved in $100 \mu \mathrm{l}$ of PEG200/DMSO (7:3; v:v). This dose level was chosen because it was non toxic (based on body weights) when administered i.p. (daily X 5) for 2 consecutive weeks and also because this dose was found active in Lewis lung carcinoma bearing mice [9]. Blood samples ( $\mathrm{n}=3$ per sampling time) were collected by cardiac puncture with heparinized syringes after sacrificing the animals by $\mathrm{CO}_{2}$ at the following times: pre-administration (time 0 ), and at $0.25,0.5,1$, 
$1.5,2,4,8,15$ and $24 \mathrm{~h}$ post-dosing. Blood samples were transferred into polypropylene tubes and centrifuged at $12,000 \mathrm{~g}$ for $10 \mathrm{~min}$ to obtain the plasma which was kept at $-20^{\circ} \mathrm{C}$ until HPLC analysis. For the determination of fisetin and metabolites in tumors, pieces of Lewis lung carcinoma (LLC) were injected subcutaneously into the right flank of female C57BL/6J mice $\left(5 \mathrm{~mm}^{3}\right)$ on day 0 . Fifteen days later, when the tumors reached a volume of $500-1000$ $\mathrm{mm}^{3}$, mice were injected with fisetin $(223 \mathrm{mg} / \mathrm{kg}$, i.p.) dissolved in $100 \mu \mathrm{l}$ of polyethylene glycol 200/DMSO (7:3; v:v), and 15 min later, the mice were sacrificed and the tumors were harvested, rinsed with ice-cold PBS and transferred into a polypropylene tube and kept at $20^{\circ} \mathrm{C}$ until analysis. All animal experiments have been carried out in accordance with institutional and French regulations concerning the protection of animals used for experimental and other scientific purposes, and with the European Commission regulations.

\subsection{Sample preparation and extraction}

Plasma samples, tumor or normal tissues homogenates (prepared with $1 \mathrm{ml}$ of PBS using a Teflon potter at a speed of $50 \mathrm{rpm}$ with 3 strokes), were extracted by mixing (Vortex mixer, 1 min) with a 5-fold volume of cold methanol containing kaempferol (3,4',5,7tetrahydroxyflavone, Fig. 1), as an internal standard (final concentration $3.3 \mu \mathrm{g} / \mathrm{ml}$ ). The mixture was put on ice for one hour to precipitate the proteins, and the samples were centrifuged at $12,000 \mathrm{~g}$ for $10 \mathrm{~min}$ at $4^{\circ} \mathrm{C}$. The upper phase was transferred to another polypropylene tube and $100 \mu \mathrm{l}$ was injected onto a Shimadzu HPLC-UV system described below.

\subsection{Standard curves and extraction}

Stock solutions of fisetin, geraldol and kaempferol (cf., Fig. 1) were prepared in methanol at $100 \mu \mathrm{g} / \mathrm{ml}$ and stored at $-20{ }^{\circ} \mathrm{C}$ in the dark. Working standard solutions of increasing 
concentrations of fisetin and geraldol were prepared on the day of analysis by diluting the stock solution. The standard curves of fisetin and geraldol in mouse plasma, tumors, or normal tissues, were built using the ratio of the area of fisetin or geraldol over the area of the internal standard (kaempferol) and were linear within the concentration range used ( 0.01 to 20 $\mu \mathrm{g} / \mathrm{ml}$ ) with correlation coefficient $>0.99$. The percent extraction from plasma, tumors, or normal tissues was $91 \%$ and the lower limit of quantification was $0.01 \mu \mathrm{g} / \mathrm{ml}$. The apparent concentration of the metabolites was calculated based on the fisetin standard curve.

\subsection{HPLC system for pharmacokinetic studies}

For pharmacokinetic studies we used a HPLC-UV system (Shimadzu CLASS-VP ${ }^{\circledR}$, version 5.3), equipped with a $\mathrm{C}_{18}$ column (Beckman Ultrasphere ODS, $5 \mu \mathrm{m} ; 4.6 \times 25 \mathrm{~mm}$ ) thermostated at $20^{\circ} \mathrm{C}$, and a UV detector set at $360 \mathrm{~nm}$. The mobile phase was composed of $52 \%$ methanol, $48 \%$ aqueous acetic acid (2\%), at a flow rate of $1 \mathrm{ml} / \mathrm{min}$.

\subsection{Pharmacokinetic parameters determination}

Fisetin plasma concentrations were analyzed using non compartmental analysis and also using a bicompartmental model with extravascular administration. The following non compartmental pharmacokinetics parameters were derived using standard methods [27]: area under the plasma concentration versus time curve from time zero to the time of the last measurable concentration $\left(\mathrm{AUC}_{0-\mathrm{t}}\right)$ calculated by the trapezoidal method; maximum concentration $\left(\mathrm{C}_{\max }\right)$; mean residence time $(\mathrm{MRT})$; terminal half-life; apparent intraperitoneal clearance $(\mathrm{CL} / \mathrm{F})$ and volume of distribution at steady state (Vss/F). Pharmacokinetics parameters were also determined by fitting the fisetin plasma concentration versus time to a two-compartmental model with extravascular administration using the Graph Pad Prism software. 


\subsection{Identification of metabolites}

2.7.1 Hydrolysis of glucuronide conjugates. To hydrolyze glucuronide conjugates, plasma or tumor homogenate samples were adjusted to $\mathrm{pH} 5.0$ with an equal volume of $50 \mathrm{mM}$ acetate buffer, and incubated at $37^{\circ} \mathrm{C}$ for $2 \mathrm{~h}$ in the presence of 1000 units of $\beta$-glucuronidase (Sigma No. G-0751). The hydrolyzed samples were submitted to the above described protocol of methanolic extraction and injected onto the HPLC system.

\subsubsection{Identification of metabolite M3 using UV and mass spectrometry. Metabolite M3} was analyzed online using an HPLC-MS/MS system composed of an HPLC apparatus (Surveyor $^{\circledR}$, ThermoElectron) equipped with a UV diode array detector and coupled with a mass spectrometer (LCQ-Advantage ${ }^{\circledR}$, ThermoElectron). A $\mathrm{C}_{18}$ reversed-phase column (EC. 250/2 Nucleodur Sphinx RP, $5 \mu \mathrm{m}, 250 \mathrm{~mm}$ X $2.1 \mathrm{~mm}$, Macherey-Nagel) thermostated at $30^{\circ} \mathrm{C}$ was used. The metabolites (injection volume: $15 \mu \mathrm{l}$ ) were resolved with the following ternary gradient using methanol (A), acetonitrile (B) and aqueous $0.1 \% \mathrm{TFA}(\mathrm{C})$ at a flow rate of $0.2 \mathrm{ml} / \mathrm{min}$ : from 0 to $50 \mathrm{~min}, 7-35 \% \mathrm{~A}, 4-19 \% \mathrm{~B}, 89-46 \% \mathrm{C}$; from 50 to $60 \mathrm{~min}, 35 \% \mathrm{~A}$, $19 \% \mathrm{~B}, 6 \% \mathrm{C}$ (gradient 1). The mass spectrometer consisted of an electrospray ionization system used in positive ion polarity mode and ion trap mass analyzer. The operating parameters where as follows: the spray needle voltage was set at $4.0 \mathrm{kV}$ and the spray was stabilized with a nitrogen sheath gas. Electrospray capillary voltage was $4.0 \mathrm{~V}$, nitrogen was used as auxilliary gas, and the capillary temperature was $250^{\circ} \mathrm{C}$. The Xcalibur ${ }^{\circledR}$ software was used for data acquisition and analysis. 
2.7.3 Identification of $\mathrm{M3}$ using retention times in various gradient systems. To ascertain the identity of M3, this metabolite and authentic geraldol were separately injected using the HPLC system with gradient 1 described in section 2.7.2, and three other ternary gradients composed of methanol (A), acetonitrile (B) and aqueous $0.1 \%$ TFA (C) (flow rate $0.2 \mathrm{ml} / \mathrm{min}$ ) as follows: gradient 2- from 0 to $70 \mathrm{~min}, 7-35 \% \mathrm{~A}, 4-19 \% \mathrm{~B}, 89-46 \% \mathrm{C}$; gradient 3- from 0 to 50 min, $15-35 \% \mathrm{~A}, 10-19 \% \mathrm{~B}, 75-46 \% \mathrm{C}$; gradient $4-$ from 0 to $70 \mathrm{~min}, 15-35 \% \mathrm{~A}, 10-19 \%$ B, $75-46 \%$ C. For each gradient, the logarithm of the retention factor (log k) of M3 and geraldol were calculated using retention time and dead time. The retention factor relates to retention time, but is preferred because it is dimensionless and independent of unexpected variations in mobile phase flow. In contrast to retention time, the $\log \mathrm{k}$ can unequivocally be ascribed to structural changes, as previously used for flavonoids by Stefova et al., 2007 [28]. To further ascertain the identity of M3, we also injected an equimolar mixture of geraldol and M3 using all 4 gradient systems.

\subsection{In vitro cytotoxic activity of fisetin and metabolite}

The murine Lewis lung carcinoma (LLC) cell line, the normal NIH 3 T3 murine fibroblast cell line and the EAhy 926 endothelial cell line were grown in Dulbecco's modified Eagle's medium (DMEM) containing $2 \mathrm{mM} \mathrm{L-glutamine,} \mathrm{10 \%} \mathrm{fetal} \mathrm{bovine} \mathrm{serum,} 100 \mathrm{U} / \mathrm{ml}$ penicillin and $100 \mu \mathrm{g} / \mathrm{ml}$ streptomycin $\left(37^{\circ} \mathrm{C}, 5 \% \mathrm{CO}_{2}\right)$. Exponentially growing cells were plated onto 96-well plates at 5000 cells per well in $200 \mu$ l. Twenty-four h later, cells were exposed for 24 or $48 \mathrm{~h}$ to fisetin or geraldol at increasing concentrations (0 to $1 \mathrm{mM}$ ). Viability was assessed using the MTT test and absorbance was read at $562 \mathrm{~nm}$ in a microplate reader (BioKinetics Reader, EL340). Appropriate controls with DMEM only and MTT were run to subtract background absorbance. Experiments were run in quadruplicate and repeated 3 times. Control cells were exposed to $1 \%$ DMSO which was not cytotoxic. The results are 
presented as the inhibitory concentrations for $50 \%$ of cells $\left(\mathrm{IC}_{50}\right)$ for a 24 or $48 \mathrm{~h}$ exposure time relative to controls.

\subsection{Cell migration assay (scratch wound assay)}

EAhy 926 endothelial cells were grown to confluence and a wound was introduced by clearing an area of the monolayer using a $100 \mu$ pipet tip. After wounding, digital photographs were recorded of wounded areas of each well at a magnification of X 100 (time 0 h). Medium was changed, and bFGF (10 ng/ml), fisetin or geraldol was added at increasing concentrations $(0,22,44$ and $88 \mu \mathrm{M})$ to the media containing $2.5 \%$ of FBS. After a $24 \mathrm{~h}$ incubation period, digital photographs were recorded of the cleared areas of each well. Migration was evaluated by manually drawing the distance of the wound area (d) at $T_{0 h}$ and $\mathrm{T}_{24 \mathrm{~h}}$ time on a computer screen and distances values were obtained using the ImageJ software [29]. The results were expressed as a percent of the controls using the following formula: 100 $\times\left[1-\left(\mathrm{dT}_{0 \mathrm{~h}}-\mathrm{dT}_{24 \mathrm{~h}}\right.\right.$ of treated cells $) /\left(\mathrm{dT}_{0 \mathrm{~h}}-\mathrm{dT}_{24 \mathrm{~h}}\right.$ of control cells $\left.)\right]$. Experiments were performed in triplicate for each concentration and were repeated 3 times.

\subsection{Formation of capillary-like structures}

Analysis of capillary-like structure formation was performed using EAhy 926 endothelial cells grown on Matrigel. Fifty $\mu$ l of the Matrigel solution was applied to each well on a 96well plate and incubated for $30 \mathrm{~min}$ at $37^{\circ} \mathrm{C}$. EAhy 926 cells $\left(1 \times 10^{4}\right)$ were suspended in 100 $\mu 1$ of medium, plated onto the gel matrix and incubated at $37^{\circ} \mathrm{C}$. Adherent cells received bFGF $(10 \mathrm{ng} / \mathrm{ml})$ and fisetin or geraldol at increasing concentrations $(0,22,44$ and $88 \mu \mathrm{M})$. After a $24 \mathrm{~h}$ exposure time, in vitro angiogenesis was assessed by counting the capillary-like structures in each well at X 100 magnification under a light microscope (Zeiss). The in vitro anti-angiogenic effect was calculated by the following formula: $100 \times[1$-(number of 
capillary-like tube of treated cells) / (number of capillary-like tube of control cells)]. Experiments were performed in duplicate for each condition and repeated 3 times.

\subsection{Statistical analysis}

Results are expressed as the mean \pm SEM of at least 3 independent experiments. Statistical differences between means were assessed using the Student $t$ test for unpaired data. If unequal variance was observed, the Welch's correction was applied. A P value $\leq 0.05$ was considered significant. 


\section{Results}

\subsection{Plasma and tissue pharmacokinetics of fisetin and its metabolites}

A representative chromatogram depicting the separation of fisetin and its metabolites in mouse plasma is presented in Figure 2. In these chromatographic conditions (reversed-phase mode), fisetin eluted at $40 \mathrm{~min}$ and the internal standard (kaempferol) at $53 \mathrm{~min}$. Fisetin plasma pharmacokinetics after an i.p. administration at a dose of $223 \mathrm{mg} / \mathrm{kg}$ is presented in Figure 3 and Table 1. The maximum plasma concentration reached $2.53 \mu \mathrm{g} / \mathrm{ml}$ at $15 \mathrm{~min}$ post dosing and declined thereafter with a first rapid alpha half-life of $0.09 \mathrm{~h}$ (5.4 min), followed by a longer terminal disposition half-life beta of $3.12 \mathrm{~h}$. The total area under the plasma versus time curve $(\mathrm{AUC})$ was $4.0 \mu \mathrm{g} \times \mathrm{h} / \mathrm{ml}$, the apparent intraperitoneal clearance $(\mathrm{CL} / \mathrm{F})$ was $1.12 \mathrm{~L} / \mathrm{h}$, and the $\mathrm{Vss} / \mathrm{F}$ was $5.1 \mathrm{~L}$.

As shown in Figure 2, in addition to the fisetin peak, several other peaks not present in control plasma were also detected. Of those peaks, two metabolites eluted before fisetin (M1 at $26 \mathrm{~min}$ and M2 at $35 \mathrm{~min}$ ), whereas another metabolite (M3) eluted after fisetin with a retention time of $48 \mathrm{~min}$. Figure 4 presents the relative concentrations of these metabolites as a function of time using fisetin as a reference. It can be observed that metabolites M1 and M2 could achieve apparent higher concentrations than the parent compound, whereas metabolite M3 apparent concentrations were lower compared to fisetin. Pharmacokinetic parameters of the metabolites are presented in Table 1.

To obtain some information on fisetin and metabolites levels in normal tissues, mice were sacrificed 30 minutes after i.p. injection of fisetin and liver, intestines, kidneys, lungs and spleen were harvested. Fisetin and metabolites levels presented in Table 2 show that fisetin concentrations were highest in liver, intestines and kidneys. Metabolite M1 highest 
concentrations were mainly found in plasma and kidneys. For metabolites M2 and M3, the highest concentrations were in kidneys and intestines.

We next submitted plasma samples to $\beta$-glucuronidase digestion, and the M1 and M2 metabolite peaks were completely abolished, whereas the fisetin and the M3 peaks were markedly increased as shown in Figure 5 (compare with Fig. 2 without $\beta$-glucuronidase). This observation indicated that M1 and M2 were glucuronides of fisetin and metabolite M3, respectively.

\subsection{Identification of metabolite M3}

To identify metabolite M3, the peak at 48 min was subjected on line to mass spectrometry analysis and UV spectrum determination. The mass spectrum of M3 presented a molecular ion $\mathrm{m} / \mathrm{z}$ value of $301 \mathrm{Da}[\mathrm{M}+\mathrm{H}]^{+}$, thus corresponding to a molecular weight of $300 \mathrm{Da}$ (Figure 6-A). In the same conditions, fisetin presented a $\mathrm{M}+\mathrm{H} m / z$ value of $287 \mathrm{Da}$ corresponding to a molecular weight of $286 \mathrm{Da}$ (data not shown). Therefore, the gain of 14 atomic mass units observed with M3 over the parent compound corresponded to the addition of a $\mathrm{CH}_{2}$ on the fisetin molecule, indicating that metabolite M3 was a methylated compound of fisetin. However, because fisetin possesses 4 hydroxyl groups, the exact localization of the methoxyl on the fisetin molecule could not easily be identified.

In addition, the UV spectrum of M3 was found superimposable to that of fisetin with identical maxima at 245, 320 (shoulder) and $360 \mathrm{~nm}$ (Figure 6-B). Among the possible methylated fisetin candidates, the 3,4',7-trihydroxy-3'-methoxyflavone or geraldol (cf. Figure 1), therefore appeared as a possible candidate. Geraldol UV spectrum was indeed found 
superimposable to that of M3 and fisetin (Figure 6-B). Also the mass spectrum of authentic geraldol was also superimposable to the mass spectrum of M3 (data not shown).

Authentic geraldol was also tested for its HPLC retention time and it was found to co-elute with metabolite M3 in 4 different ternary elution systems (Table 3), thus further substantiating that M3 was indeed geraldol. In addition, the logarithm of the retention factor (log k) of M3 and geraldol yielded the same values, further substantiating the identity of M3 as geraldol. Considering M3 molecular mass identical to geraldol, its UV spectrum superimposable to both fisetin and geraldol spectra, its retention times and $\log \mathrm{k}$ identical to authentic geraldol in 4 ternary gradient systems, allowed us to ascribe M3 as being geraldol.

\subsection{Tumor concentration of fisetin and its metabolites}

At $15 \mathrm{~min}$ after the administration of fisetin i.p. $(223 \mathrm{mg} / \mathrm{kg})$ to tumor bearing mice (Lewis lung carcinoma), the plasma and tumor concentrations of fisetin and its main metabolites were also determined by HPLC. Glucuronides M1 and M2 presented higher concentrations in the plasma compared to tumors (compare Figures 7A and 7B). However, it was of interest to note that geraldol was the metabolite that reached the highest concentrations in tumors (Figure 7-

B). Indeed, geraldol concentrations in tumors were 4.3 times higher than the fisetin concentration in this tissue at this sampling time. Considering this observation, we were next interested to investigate further the geraldol cytotoxic and antiangiogenic properties.

\subsection{Cytotoxic activity of fisetin and geraldol on Lewis lung carcinoma (LLC) cells, endothelial cells (EAhy 926), and normal cells (NIH 3T3)}


The effect of fisetin and metabolite geraldol on the viability of Lewis carcinoma cells, endothelial cells (EAhy 926), and normal NIH 3 T3 cells were also tested (Figure 8). A dosedependent decrease in viability of the three cell lines after a $24 \mathrm{~h}$ exposure time to both flavonoids could be observed. The most cytotoxic flavonoid on LLC cells was found to be geraldol with an $\mathrm{IC}_{50}$ (the concentration producing $50 \%$ reduction of viability) of $24 \mu \mathrm{M}$, about 2.5-fold lower than that of fisetin $(59 \mu \mathrm{M})$ (Fig. 8-A). Concerning the effect on EAhy 926 endothelial cells viability, fisetin and geraldol showed similar $\mathrm{IC}_{50}$ (76 and $72 \mu \mathrm{M}$, respectively) (Fig. 8-B). However, it was of interest that the normal NIH 3T3 cells were significantly less sensitive to fisetin and geraldol than either LLC or endothelial cells, with $\mathrm{IC}_{50}$ of $195 \mu \mathrm{M}$ and $128 \mu \mathrm{M}$, respectively (Fig. 8-C).

\subsection{Fisetin and geraldol effect on endothelial cells migration in vitro}

We next compared the effect of various concentrations $(22,44,88 \mu \mathrm{M})$ of fisetin and its metabolite geraldol on EAhy 926 endothelial cells migration using the scrape wound assay. Figure 9 illustrates that at 24 h post-wounding of confluent EAhy 926 endothelial cells, the control bFGF $(10 \mathrm{ng} / \mathrm{ml})$ treated cells migrated and totally filled the scraped area, as expected. Although fisetin and geraldol could inhibit significantly endothelial cells migration at $44 \mu \mathrm{M}$

(Figure 9), fisetin was found more active than geraldol at this concentration, and also at the lower concentration of $22 \mu \mathrm{M}$ (Figure 10). Although the inhibition of endothelial cells migration was dose-dependent for both flavonoids, the calculated $\mathrm{IC}_{50}$ for the antimigration effect showed that fisetin had a significantly $(p<0.001)$ stronger antimigration effect compared to geraldol (43 $\pm 0.8 \mu \mathrm{M}$ versus $64 \pm 0.8 \mu \mathrm{M}$, respectively) (Figure 10).

\subsection{Fisetin and geraldol effect on the capillary-like structure formation on Matrigel}


To examine whether geraldol could directly inhibit angiogenesis, its effect on bFGF-mediated tube formation by endothelial cells was investigated at concentrations ranging from 3 to 300 $\mu \mathrm{M}$. As expected, EAhy 926 endothelial cells plated on Matrigel with bFGF $(10 \mathrm{ng} / \mathrm{ml})$ formed a capillary-like network within $24 \mathrm{~h}$ (data not shown). Fisetin could prevent the formation of the capillary-like network in a dose-dependent fashion with an $\mathrm{IC}_{50}$ of $51 \pm 7$ $\mu \mathrm{M}$, whereas no significant antiangiogenic effect of geraldol could be observed at the highest achievable in vitro concentration of $88 \mu \mathrm{M}$, because geraldol was not soluble at higher concentrations (data not shown). 


\section{Discussion}

The natural flavonoids are attracting interest in cancer prevention and therapy because these compounds are relatively non toxic compared to other chemotherapeutic agents used in cancer therapy [1-4]. Although the dietary flavonoid fisetin has recently been shown to be an interesting anticancer active agent in mice [7-9] and to possess antiangiogenic properties in vitro [12;13] and in vivo [9], the blood levels achieved by this compound after systemic administration and its metabolism have not previously been investigated in mice. The purpose of this study was therefore to study fisetin pharmacokinetics in mice, to determine fisetin principal metabolic routes and to evaluate the biological activity of a detected metabolite.

Concerning the pharmacokinetics of fisetin in mouse plasma, we found that it could reach a concentration of $2.5 \mu \mathrm{g} / \mathrm{ml}$ at $15 \mathrm{~min}$ and that it displayed a relatively long terminal half-life in plasma of $3.12 \mathrm{~h}$ after an i.p. administration of $223 \mathrm{mg} / \mathrm{kg}$. Although the plasma concentrations are relatively low, it is possible that the long residence time could be responsible for the remarkable in vivo antitumor effect in mice at this dose level [9]. Nonlinear pharmacokinetics may also be involved in the fisetin long residence time at this dose level, as nonlinear pharmacokinetics has already been reported for other flavonoids [30]. Potential accumulation of fisetin and/or metabolites in tumour tissue could also play a role in the fisetin antitumour activity. Compared to fisetin pharmacokinetics in rat in which negligible levels of free fisetin and a short half-life of 2.7 minutes were reported [31], it thus appears that the mouse is eliminating fisetin at a much slower rate (half-life $=3.12$ hours), probably due to a lower conjugation capacity through glucuronidation in mice. Indeed, such significant species differences in clearance has also been observed for the flavonoid analogue 5,6-dimethylxanthenone-4-acetic acid (DMXAA), which is also mainly metabolized through glucuronidation, where in vitro intrinsic clearance in mice was found to be 15 -fold lower that 
in rats, and in vivo plasma clearance was 1.8 -fold smaller in mice compared to rat plasma clearance [32].

We also observed that metabolites M1 and M2, which were identified as glucuronides, displayed longer terminal half-lives compared to fisetin. This appears unusual since these two metabolites are glucuronides of fisetin and M3, and shorter half-lives could have been expected. However such a pharmacokinetic behaviour has also been reported for fisetin in rats where a half-life of 2.7 min was found for the aglycone, whereas the glucuronides were showing a half-life of 40.7 min [31]. Such a longer half-life for genistein sulfates/glucuronides has also been observed in rats compared to the parent aglycone [33].

In this study, we have also identified a methylated metabolite of fisetin which was assigned to the 3,4',7-trihydroxy-3'-methoxyflavone (geraldol). This metabolite, reported here for the first time to our knowledge, is probably generated through catechol- $O$-methyl transferase (COMT) metabolism because fisetin possesses a catechol function on the B ring. COMT catalyzes the transfer of a methyl group from $S$-adenosyl-L-methionine to polyphenols possessing an $o$-diphenolic (catechol) moiety. COMT can be found as membrane bound and soluble forms and is expressed in brain and most peripheral tissues including liver, kidneys and small intestine in the mouse, although there are large differences between species $[34 ; 35]$. Methylation has already been reported for other flavonoids possessing a catechol function, e.g., quercetin, catechin, caffeic acid, and luteolin (reviewed in [35]). Methylation of flavonoids generally occurs predominantly in the 3'-position of the polyphenol, but a minor proportion of 4'-O-methylated product can also be formed.

Although our mass spectrometry data indicated the presence of a methoxyl group on the fisetin molecule, the exact position of this substituent could not be determined by this technique alone. The formal identification of the methoxylated metabolite of fisetin was therefore further investigated using UV spectroscopy which is particularly useful for the 
identification of flavonoids [36]. It is known that methylation of hydroxyl groups in positions 3, 5, 7, or 4' produces hypsochromic shifts (shorter wavelengths) of the characteristic absorption bands in the UV-spectra of flavones, but does not significantly affect the shape of the UV-spectra when it occurs in other positions [37]. In our case, metabolite M3 did not present a hypsochromic shift compared to the parent compound and their UV spectra were superimposable. Therefore, the methylation of the $3,4^{\prime}$, and the 7 positions could therefore be ruled out as possible methylated positions of fisetin.

We further ascertained the identity of metabolite M3 as being the 3,4',7-trihydroxy-3'methoxyflavone or geraldol using the log k value obtained by reversed-phase HPLC. It was already demonstrated that $\log \mathrm{k}$ values are significantly different for the same flavone if methylated in the 3' or the 4' position [28]. Using the same approach, the log $\mathrm{k}$ values obtained with 4 different ternary mobile phases were strictly identical for geraldol and metabolite M3, therefore substantiating further that M3 was indeed the 3'-methyl-fisetin, and could not be the 4'-methyl-fisetin. Concerning the possible methylation on position 3 of fisetin, this would have resulted in a decrease in the retention time in the reversed-phase HPLC mode, owing to its inductive effect which increases the influence of the polar carbonyl group [28]. Methylation of the hydroxyl group in position 3 results in a lack of hydrogen bonding between 3-OH and the carbonyl group (at $\mathrm{C} 4$ ) which results in an increased polarity of the molecule and consequently a decreased in retention time. In contrast, an increase in retention time was observed compared to fisetin, which further rules out a methylation at the 3 position of fisetin. Considering metabolite M3 molecular mass M3 identical to geraldol, its UV spectrum identical to fisetin and geraldol, and identical retention times to geraldol in 4 different ternary gradient systems, the identity of M3 was therefore assigned to geraldol.

Of particular interest, it was also observed that this 3'-methoxylated metabolite of fisetin could achieve higher concentrations in tumors compared to fisetin, an observation probably 
linked to the fisetin in vivo remarkable anticancer activity already noted by some investigators [7-9]. This high tumor geraldol levels could result from either an increased in situ formation or this metabolite, or from hydrolysis of its glucuronide that could regenerate the aglycone. Indeed, a high COMT activity in the tumor is possible because an increased expression of this enzyme has recently been observed in cancer [38]. Concerning the possible regeneration of the aglycone from its corresponding glucuronide, it has been reported that Lewis lung tumors express a high $\beta$-glucuronidase activity that could hydrolyze the glucuronide to its geraldol aglycone [39].

From a metabolic standpoint, the methylation of fisetin in vivo could be viewed as a favourable metabolic route, because methylation usually results in a higher metabolic stability of flavonoids that could favour its retention in vivo [40]. Because geraldol can be glucuronidated, as shown in this work, and could therefore be secreted in bile, bacterial glucuronidase present in the intestines could hydrolyze this metabolite and give back the aglycone (geraldol) that could be absorbed from the intestines, therefore possibly contributing to a longer residence time in vivo for this metabolite. In addition, the presence of a methoxy group on the A or B ring of the flavonoid also seems to protect the structure from bacterial degradation in faeces, therefore probably contributing to longer exposure times in vivo by allowing the reabsorption from the intestines of the intact methylated metabolite [41].

However, we observed in this work that the geraldol formed in vivo is rapidly cleared from the plasma as shown by its short half-life, although this metabolite is less polar and probably more metabolically stable than fisetin. We have no obvious explanation for this observation, except that upon geraldol formation in vivo, this metabolite could be rapidly metabolized to other metabolites (e.g., glucuronides and/or sulfates), which could perhaps explain its rapid clearance. 
The fisetin antiproliferative/cytotoxic activity determined in this study on Lewis lung carcinoma cells is in line with its cytotoxic activity reported on other cancer cell lines, e.g., in prostate [17], liver [16], colon [18], and leukemia cell lines [14]. With regard to the comparison of the biological activity of fisetin and its metabolite geraldol, it was of interest to note that the metabolite was more cytotoxic than the parent compound on Lewis lung carcinoma cells showing a 2.5 -fold lower $\mathrm{IC}_{50}$ value. This increased cytotoxicity of the metabolite associated with the higher concentrations of geraldol in tumor could give fisetin a selective anticancer activity advantage in vivo. Also of interest, both fisetin and geraldol were found several folds less cytotoxic towards normal NIH 3 T3 cells compared to tumor cells, and this could give these compounds an important in vivo advantage in terms of therapeutic index, because they would be less toxic to normal cells compared to cancer cells. This relative non toxicity of flavonoids to normal cells was also noted for other normal cell lines [13]. This tumor cell selectivity was also observed on prostate cancer cells that were shown to be more vulnerable to fisetin compared to normal prostate cells [17]. This relatively uncommon cancer cell selectivity could therefore confer fisetin a valuable advantage for in vivo anticancer treatment.

In addition, it should be mentioned that because of the presence of 4 hydroxyl substituents on the fisetin molecule, several glucuronide conjugates were also detected at high concentrations in mouse plasma in the present mouse study, and also in rat plasma [31]. These metabolites could also play a role in the overall antiangiogenic effects observed in vivo in mice, because some flavonoid sulfates and/or glucuronides have been reported to display bioactivities sometimes superior to their aglycones (free forms) [42-45]. Future studies aimed at determining potential high partition of metabolites and/or accumulation in tumour tissue should also be considered, as well as a more complete pharmacokinetic profile of fisetin and its metabolites in tumours should also be assessed. 
The interesting bioactivity of geraldol shown in the present work has also to be put in perspective of a recently published work on quercetin (3',3,4',5,7-pentahydroxyflavone), a close parent of fisetin bearing an additional 5-hydroxyl substituent. A 3'-O-methylated metabolite of quercetin, i.e., isorhamnetin, was shown to possess potent inhibitory activity of cyclo-oxygenase-2 (COX-2), an enzyme mechanistically linked to carcinogenesis [46]. Also in line with this observation, quercetin metabolites have been found to possess antioxidant properties [47-49], and to inhibit xanthine oxidase and lipoxygenase [50].

Regarding the effect of fisetin and geraldol on the formation of capillary-like structures, the parent compound fisetin has previously been shown to be active in this model [9], whereas geraldol could not achieve an active concentration in this model probably due to its inherently low water solubility. It is however possible that longer exposure time to geraldol $(>24 \mathrm{~h})$ could nonetheless participate to an antiangiogenic response in vitro. Considering the above results, it is therefore possible that fisetin antitumor action in vivo could involve a dual mechanism of action, i.e., the parent compound fisetin would exert its strong antiangiogenic action directly, whereas its main metabolite geraldol would then exert its strong cytotoxicity against tumor cells.

In conclusion, we have determined fisetin pharmacokinetics in mice, for the first time to our knowledge, and have also identified geraldol, a previously unknown metabolite. In addition, we have shown that the metabolite geraldol possesses interesting biological activities in terms of selective cytotoxicity on cancer cells, antiproliferative and antimigration effects on endothelial cells. Fisetin and geraldol anticancer and antiangiogenic properties therefore deserve to be optimized in preclinical models, as a single administration or in combination therapy with cytotoxic anticancer agents. 
Acknowledgements. This research was supported by the Institut national de la santé et de la recherche médicale (Inserm), by the Centre national de la recherche scientifique (CNRS), and by a grant from the French National Cancer Institute (Institut National $d u$ Cancer, Boulogne-Billancourt, France). 


\section{REFERENCES}

[1] Havsteen BH. The biochemistry and medical significance of the flavonoids. Pharmacol Ther 2002;96:67-202.

[2] Hill S, Williams KB, Denekamp J. Vascular collapse after flavone acetic acid: a possible mechanism of its anti-tumour action. Eur J Cancer Clin Oncol 1989;25:141924.

[3] Lopez-Lazaro M. Flavonoids as anticancer agents: structure-activity relationship study. Curr Med Chem Anticancer Agents 2002;2:691-714.

[4] Middleton E, Jr., Kandaswami C, Theoharides TC. The effects of plant flavonoids on mammalian cells: implications for inflammation, heart disease, and cancer. Pharmacol Rev 2000;52:673-751.

[5] Arai Y, Watanabe S, Kimira M, Shimoi K, Mochizuki R, Kinae N. Dietary intakes of flavonols, flavones and isoflavones by Japanese women and the inverse correlation between quercetin intake and plasma LDL cholesterol concentration. J Nutr 2000;130:2243-50.

[6] Kimira M, Arai Y, Shimoi K, Watanabe S. Japanese intake of flavonoids and isoflavonoids from foods. J Epidemiol 1998;8:168-75.

[7] Khan N, Asim M, Afaq F, Abu ZM, Mukhtar H. A novel dietary flavonoid fisetin inhibits androgen receptor signaling and tumor growth in athymic nude mice. Cancer Res 2008;68:8555-63.

[8] Tripathi R, Samadder T, Gupta S, Surolia A, Shaha C. Anti-cancer activity of a combination of cisplatin and fisetin in embryonal carcinoma cells and xenograft tumors. Mol Cancer Ther 2011;10:255-68.

[9] Touil YS, Seguin J, Scherman D, Chabot GG. Improved antiangiogenic and antitumour activity of the combination of the natural flavonoid fisetin and 
cyclophosphamide in Lewis lung carcinoma-bearing mice. Cancer Chemother Pharmacol 2010;DOI: 10.1007/s00280-010-1505-8:-In Press.

[10] Woodman OL and Chan EC. Vascular and anti-oxidant actions of flavonols and flavones. Clin Exp Pharmacol Physiol 2004;31:786-90.

[11] Park HH, Lee S, Oh JM, Lee MS, Yoon KH, Park BH, Kim JW, Song H, Kim SH. Anti-inflammatory activity of fisetin in human mast cells (HMC-1). Pharmacol Res 2007;55:31-7.

[12] Touil YS, Fellous A, Scherman D, Chabot GG. Flavonoid-induced morphological modifications of endothelial cells through microtubule stabilization. Nutr Cancer 2009;61:310-21.

[13] Fotsis T, Pepper MS, Aktas E, Breit S, Rasku S, Adlercreutz H, Wahala K, Montesano R, Schweigerer L. Flavonoids, dietary-derived inhibitors of cell proliferation and in vitro angiogenesis. Cancer Res 1997;57:2916-21.

[14] Lee WR, Shen SC, Lin HY, Hou WC, Yang LL, Chen YC. Wogonin and fisetin induce apoptosis in human promyeloleukemic cells, accompanied by a decrease of reactive oxygen species, and activation of caspase 3 and $\mathrm{Ca}^{2+}$-dependent endonuclease. Biochemical Pharmacology 2002;63:225-36.

[15] Kuntz S, Wenzel U, Daniel H. Comparative analysis of the effects of flavonoids on proliferation, cytotoxicity, and apoptosis in human colon cancer cell lines. Eur J Nutr $1999 ; 38: 133-42$.

[16] Chen YC, Shen SC, Lee WR, Lin HY, Ko CH, Shih CM, Yang LL. Wogonin and fisetin induction of apoptosis through activation of caspase 3 cascade and alternative expression of p21 protein in hepatocellular carcinoma cells SK-HEP-1. Arch Toxicol 2002;76:351-9. 
[17] Haddad AQ, Venkateswaran V, Viswanathan L, Teahan SJ, Fleshner NE, Klotz LH. Novel antiproliferative flavonoids induce cell cycle arrest in human prostate cancer cell lines. Prostate Cancer Prostatic Dis 2006;9:68-76.

[18] Lu X, Jung J, Cho HJ, Lim DY, Lee HS, Chun HS, Kwon DY, Park JH. Fisetin inhibits the activities of cyclin-dependent kinases leading to cell cycle arrest in HT-29 human colon cancer cells. J Nutr 2005;135:2884-90.

[19] Sung B, Pandey MK, Aggarwal BB. Fisetin, an inhibitor of cyclin-dependent kinase 6, down-regulates nuclear factor-kappaB-regulated cell proliferation, antiapoptotic and metastatic gene products through the suppression of TAK-1 and receptor-interacting protein-regulated IkappaBalpha kinase activation. Mol Pharmacol 2007;71:1703-14.

[20] Lu H, Chang DJ, Baratte B, Meijer L, Schulze-Gahmen U. Crystal structure of a human cyclin-dependent kinase 6 complex with a flavonol inhibitor, fisetin. J Med Chem 2005;48:737-43.

[21] Olaharski AJ, Mondrala ST, Eastmond DA. Chromosomal malsegregation and micronucleus induction in vitro by the DNA topoisomerase II inhibitor fisetin. Mutation Research/Genetic Toxicology and Environmental Mutagenesis 2005;582:7986.

[22] Constantinou A, Mehta R, Runyan C, Rao K, Vaughan A, Moon R. Flavonoids as DNA topoisomerase antagonists and poisons: structure-activity relationships. J Nat Prod 1995;58:217-25.

[23] Jankun J, Selman SH, Aniola J, Skrzypczak-Jankun E. Nutraceutical inhibitors of urokinase: potential applications in prostate cancer prevention and treatment. Oncol Rep 2006;16:341-6. 
[24] Böhl M, Tietze S, Sokoll A, Madathil S, Pfennig F, Apostolakis J, Fahmy K, Gutzeit HO. Flavonoids affect actin functions in cytoplasm and nucleus. Biophys $\mathbf{J}$ 2007;93:2767-80.

[25] Salmela AL, Pouwels J, Varis A, Kukkonen AM, Toivonen P, Halonen PK, Perala M, Kallioniemi O, Gorbsky GJ, Kallio MJ. Dietary flavonoid fisetin induces a forced exit from mitosis by targeting the mitotic spindle checkpoint. Carcinogenesis 2009;30:1032-40

[26] Joussen AM, Rohrschneider K, Reichling J, Kirchhof B, Kruse FE. Treatment of corneal neovascularization with dietary isoflavonoids and flavonoids. Exp Eye Res $2000 ; 71: 483-7$

[27] Gibaldi M, Perrier D. Noncompartmental analysis based on statistical moment theory. In: Ed. J.Swarbrick. Pharmacokinetics, New York and Basel: Marcel Dekker, Inc;; 1982, p. 409-17.

[28] Stefova M, Stafilov T, Kulevanova S, Stefkov G, Bankova VS. QSRR of flavones: evaluation of substituent contributions to RP HPLC retention. J Liquid Chromatography and Related Technologies 2007;30:1035-49.

[29] Abramoff MD, Magelhaes PJ, Ram SJ. Image processing with ImageJ. Biophotonics International 2004;11:36-42.

[30] Chabot GG, Bissery MC, Corbett TH, Rutkowski K, Baker LH. Pharmacodynamics and causes of dose-dependent pharmacokinetics of flavone-8-acetic acid (LM-975; NSC-347512) in mice. Cancer Chemother Pharmacol 1989;24:15-22.

[31] Shia CS, Tsai SY, Kuo SC, Hou YC, Chao PD. Metabolism and pharmacokinetics of 3,3',4',7-tetrahydroxyflavone (fisetin), 5-hydroxyflavone, and 7-hydroxyflavone and antihemolysis effects of fisetin and its serum metabolites. J Agric Food Chem 2009;57:83-9. 
[32] Zhou SF, Tingle MD, Kestell P, Paxton JW. Species differences in the metabolism of the antitumour agent 5,6-dimethylxanthenone-4-acetic acid in vitro: implications for prediction of metabolic interactions in vivo. Xenobiotica 2002;32:87-107.

[33] Piskula MK. Factors affecting flavonoids absorption. Biofactors 2000;12:175-80.

[34] Myöhänen TT and Männistö PT. Distribution and functions of catechol-Omethyltransferase proteins: do recent findings change the picture? Int Rev Neurobiol 2010;95:29-47.

[35] Manach C, Scalbert A, Morand C, Remesy C, Jimenez L. Polyphenols: food sources and bioavailability. Am J Clin Nutr 2004;79:727-47.

[36] Mabry TJ, Markham KR, Thomas MB. The systematic identification of flavonoids. New York-Heidelberg-Berlin: Springer-Verlag, 1970.

[37] Markham KR. Techniques of flavonoid identification. London: Academic Press, 1982.

[38] Hevir N, Sinkovec J, Rizner TL. Disturbed expression of phase I and phase II estrogen-metabolizing enzymes in endometrial cancer: lower levels of CYP1B1 and increased expression of S-COMT. Mol Cell Endocrinol 2011;331:158-67.

[39] Dobrossy L, Pavelic ZP, Vaughan M, Porter N, Bernacki RJ. Elevation of lysosomal enzymes in primary Lewis lung tumor correlated with the initiation of metastasis. Cancer Res 1980;40:3281-5.

[40] Wen $X$ and Walle T. Methylated flavonoids have greatly improved intestinal absorption and metabolic stability. Drug Metab Dispos 2006;34:1786-92.

[41] Lin YT, Hsiu SL, Hou YC, Chen HY, Chao PD. Degradation of flavonoid aglycones by rabbit, rat and human fecal flora. Biol Pharm Bull 2003;26:747-51.

[42] Fang SH, Hou YC, Chang WC, Hsiu SL, Chao PD, Chiang BL. Morin sulfates/glucuronides exert anti-inflammatory activity on activated macrophages and decreased the incidence of septic shock. Life Sci 2003;74:743-56. 
[43] Meng LH, Shankavaram U, Chen C, Agama K, Fu HQ, Gonzalez FJ, Weinstein J, Pommier Y. Activation of aminoflavone (NSC 686288) by a sulfotransferase is required for the antiproliferative effect of the drug and for induction of histone H2AX. Cancer Res 2006;66:9656-64.

[44] Lotito SB, Zhang WJ, Yang CS, Crozier A, Frei B. Metabolic conversion of dietary flavonoids alters their anti-inflammatory and antioxidant properties. Free Radic Biol Med 2011;In Press:doi:10.1016/j.freeradbiomed.2011.04.032.

[45] Tribolo S, Lodi F, Connor C, Suri S, Wilson VG, Taylor MA, Needs PW, Kroon PA, Hughes DA. Comparative effects of quercetin and its predominant human metabolites on adhesion molecule expression in activated human vascular endothelial cells. Atherosclerosis 2008;197:50-6.

[46] Jones DJ, Lamb JH, Verschoyle RD, Howells LM, Butterworth M, Lim CK, Ferry D, Farmer PB, Gescher AJ. Characterisation of metabolites of the putative cancer chemopreventive agent quercetin and their effect on cyclo-oxygenase activity. Br J Cancer 2004;91:1213-9.

[47] da Silva EL, Piskula MK, Yamamoto N, Moon JH, Terao J. Quercetin metabolites inhibit copper ion-induced lipid peroxidation in rat plasma. FEBS Lett 1998;430:4058.

[48] Manach C, Morand C, Crespy V, Demigne C, Texier O, Regerat F, Remesy C. Quercetin is recovered in human plasma as conjugated derivatives which retain antioxidant properties. FEBS Lett 1998;426:331-6.

[49] Merfort I, Heilmann J, Weiss M, Pietta P, Gardana C. Radical scavenger activity of three flavonoid metabolites studied by inhibition of chemiluminescence in human PMNs. Planta Med 1996;62:289-92. 
[50] Day AJ, Bao Y, Morgan MR, Williamson G. Conjugation position of quercetin glucuronides and effect on biological activity. Free Radic Biol Med 2000;29:1234-43. 
Table 1. Fisetin and metabolites pharmacokinetic parameters. ${ }^{1}$

\begin{tabular}{|l|c|c|c|c|}
\hline & & & & \\
& Cmax $(\mu \mathrm{g} / \mathrm{ml})$ & AUC $(\mu \mathrm{g} / \mathrm{ml}) \times \mathrm{h}$ & MRT (h) & Half-lives (h) \\
\hline Fisetin & 2.53 & 4.00 & 4.51 & 3.12 \\
\hline Metabolite M1 & 6.54 & 40.71 & 11.27 & 7.81 \\
\hline Metabolite M2 & 2.22 & 13.63 & 9.95 & 6.89 \\
\hline Metabolite M3 & 0.07 & 0.17 & 0.65 & 0.45 \\
\hline
\end{tabular}

Cmax, maximum plasma concentration; AUC, area under the plasma concentration versus

time curve from time zero to the time of the last measurable concentration; MRT, mean residence time. 
Table 2. Fisetin and its metabolites distribution in plasma and normal tissues in mice.

Mice were administered fisetin intraperitoneally at a dose of $223 \mathrm{mg} / \mathrm{kg}$ and tissues were harvested 30 minutes later for HPLC analyses, as detailed in the Materials and Methods section. Values are the mean \pm SEM of 3 independent determinations.

\begin{tabular}{|c|c|c|c|c|}
\hline \multirow{2}{*}{ Tissues } & \multicolumn{4}{|c|}{ Concentration ( $\mu$ g/ml or $\mu$ g/g tissue) } \\
\hline Plasma & $1.14 \pm 0.12$ & $6.12 \pm 0.47$ & $1.93 \pm 0.29$ & $0.10 \pm 0.01$ \\
\hline Liver & $39.15 \pm 12.85$ & $0.66 \pm 0.22$ & $2.02 \pm 1.31$ & $2.23 \pm 0.38$ \\
\hline Intestines & $80.11 \pm 33.82$ & $0.12 \pm 0.08$ & $4.17 \pm 3.24$ & $5.05 \pm 0.49$ \\
\hline Kidneys & $83.69 \pm 10.45$ & $4.23 \pm 1.88$ & $49.03 \pm 22.65$ & $14.25 \pm 6.54$ \\
\hline Lungs & $8.00 \pm 3.31$ & $0.69 \pm 0.46$ & $5.67 \pm 5.69$ & $1.57 \pm 0.67$ \\
\hline Spleen & $2.00 \pm 0.50$ & $1.03 \pm 1.37$ & $1.30 \pm 1.01$ & $1.71 \pm 1.67$ \\
\hline
\end{tabular}


Table 3. Retention times of fisetin and geraldol in various HPLC ternary gradient systems

\begin{tabular}{clcc}
\hline Gradient & \multicolumn{3}{c}{ Retention times in minutes $(\log \mathbf{k})^{\mathbf{b}}$} \\
\cline { 2 - 4 } system $^{\text {a }}$ & Fisetin & Geraldol & Metabolite M3 \\
\hline 1 & $40.0(0.561)$ & $47.7(0.590)$ & $47.7(0.591)$ \\
2 & $49.4(0.596)$ & $60.1(0.628)$ & $60.1(0.628)$ \\
3 & $28.6(0.504)$ & $39.0(0.557)$ & $39.0(0.557)$ \\
4 & $32.8(0.528)$ & $46.6(0.586)$ & $46.6(0.586)$ \\
\hline
\end{tabular}

${ }^{\text {a }}$ The ternary gradient systems used were composed of methanol (A), acetonitrile (B) and water containing $0.1 \%$ TFA, as follows: gradient 1 - from 0 to 50 min: $7-35 \%$ A, $4-19 \% \mathrm{~B}, 89$ $46 \% \mathrm{C}$; gradient 2- from 0 to $70 \mathrm{~min}: 7-35 \% \mathrm{~A}$; $4-19 \% \mathrm{~B} ; 89-46 \% \mathrm{C}$; gradient 3 - from 0 to $50 \min : 15-35 \% \mathrm{~A} ; 10-19 \% \mathrm{~B} ; 75-46 \% \mathrm{C}$; gradient 4 - from 0 to $70 \mathrm{~min}: 15-35 \% \mathrm{~A} ; 10-$ $19 \%$ B ; 75-46\% C. The reversed-phase HPLC system used is described in the Methods section.

${ }^{b}$ The retention factor $k$ was calculated as in Stefova et al., 2007 [27] 


\section{Legends for Figures}

Figure 1. Chemical structures of fisetin, geraldol and kaempferol. $\mathrm{R}_{1}=\mathrm{OH}, \mathrm{R}_{2}=H$, fisetin or 3,3',4',7-tetrahydroxyflavone; $\mathrm{R}_{1}=\mathrm{OCH}_{3}, \mathrm{R}_{2}=\mathrm{H}$, geraldol or 3,4',7-trihydroxy-3'methoxyflavone; $\mathrm{R}_{1}=\mathrm{H}, \mathrm{R}_{2}=\mathrm{OH}$, kaempferol or 3,4',5,7-tetrahydroxyflavone.

Figure 2. Representative HPLC chromatogram showing the separation of fisetin and its main metabolites formed in vivo (M1, M2, M3) 15 minutes after the intraperitoneal injection of fisetin at a dose of $223 \mathrm{mg} / \mathrm{kg}$. Kaempferol was used as an internal standard. In control plasma, there was no detectable peak present after the first 5 minutes.

Figure 3. Pharmacokinetic profile of fisetin in mouse plasma. After an intraperitoneal injection of $223 \mathrm{mg} / \mathrm{kg}$, fisetin concentration was determined by HPLC as described in Materials and Methods. Mean \pm SEM of 3 mice per time point. Solid line represents the fitting to an extravascular 2 compartment model.

Figure 4. Plasma concentration of the main fisetin metabolites (M1, M2 and M3) as a function of time after the intraperitoneal injection of fisetin $(223 \mathrm{mg} / \mathrm{kg})$. Fisetin and metabolites concentrations were determined by HPLC as described in Materials and Methods. The apparent concentration of the metabolites was calculated based on the fisetin standard curve. Mean \pm SEM of 3 mice per time point. Solid squares, fisetin; triangles, metabolite M1; circles, metabolite M2; diamonds, metabolite M3.

Figure 5. Representative HPLC chromatogram showing the beta-glucuronidase digestion of Metabolites M1 and M2 to yield fisetin and metabolite M3. Mice received an intraperitoneal injection of fisetin at a dose of $223 \mathrm{mg} / \mathrm{kg}$. Kaempferol was used as an internal standard.

Figure 6. Mass and UV spectra of metabolite M3. A) Representative mass spectrum of metabolite M3 obtained on line with an HPLC MS/MS equipment detailed in Materials and Methods. B) UV spectra of fisetin, metabolite M3, and geraldol obtained online using a diode array detector. 
Figure 7. A) Plasma and B) tumor concentrations of fisetin and its main metabolites M1, M2 and M3 (geraldol), 15 min after the i.p. administration of fisetin (223 mg/kg). M1 and M2 are glucuronides of fisetin and geraldol, respectively, whereas M3 is geraldol. Concentrations were determined by HPLC as described in the Materials and Methods.

Figure 8. Comparative cytotoxicity of fisetin and geraldol on various cell lines.

Figure 9. Effect of fisetin and its metabolite geraldol on endothelial cell migration (scratch wound assay). Confluent EAhy 926 endothelial cells were grown to confluence and an area was cleared using a $100 \mu \mathrm{l}$ pipet tip. Digital photographs were recorded at a magnification of $\mathrm{X} 100$ at time 0 and 24 hours later after the addition of bFGF (10 ng/ml) for the control, or with bFGF plus $44 \mu \mathrm{M}$ of either fisetin or geraldol. Scale bar, $40 \mu \mathrm{m}$.

Figure 10. Comparative antimigration effects of fisetin and its metabolite geraldol. Endothelial EAhy 926 cells were grown to confluence and cell wounding was induced using a pipet tip, as described in Materials and Methods. After a $24 \mathrm{~h}$ exposure time at the indicated concentrations of fisetin (hatched bars) and geraldol (open bars) in presence of bFGF, the relative antimigration effect was calculated as described in Materials and Methods. Mean \pm SEM of 3 independent experiments. Asterisks indicate a statistically significant difference relative to controls at the $\mathrm{P}<0.05\left(^{*}\right)$ or $\mathrm{P}<0.001(* * *)$ level (Student $t$ test). 


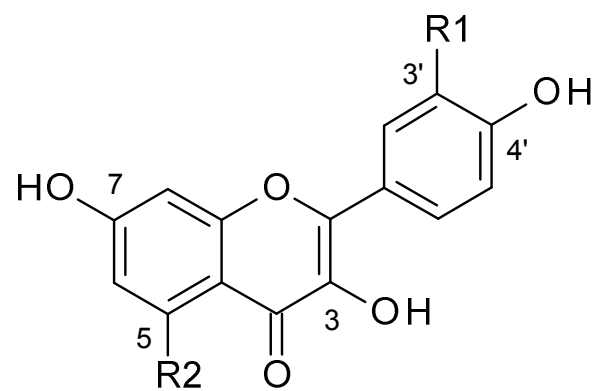

Figure 1, Touil et al. 


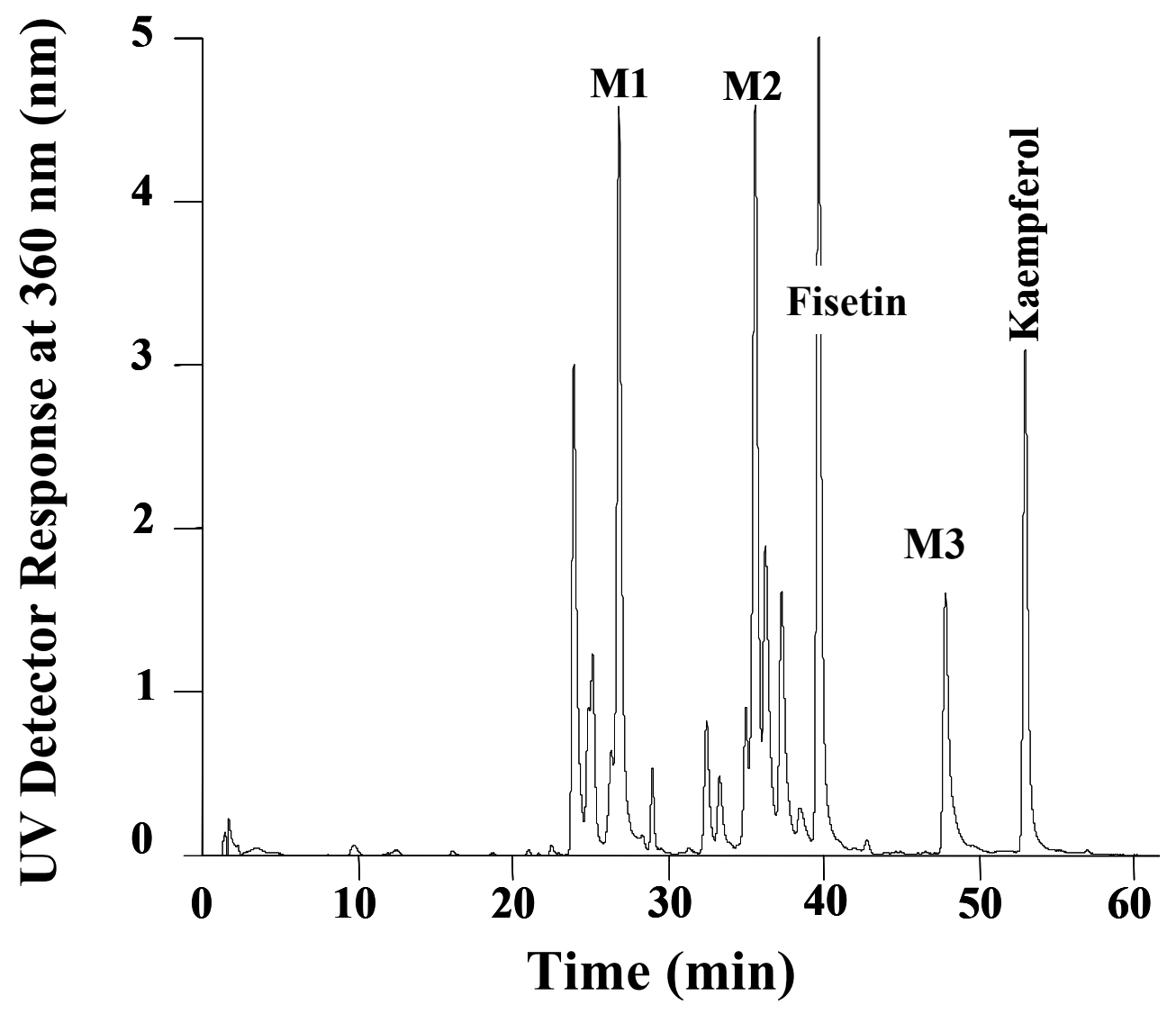

Figure 2, Touil et al. 


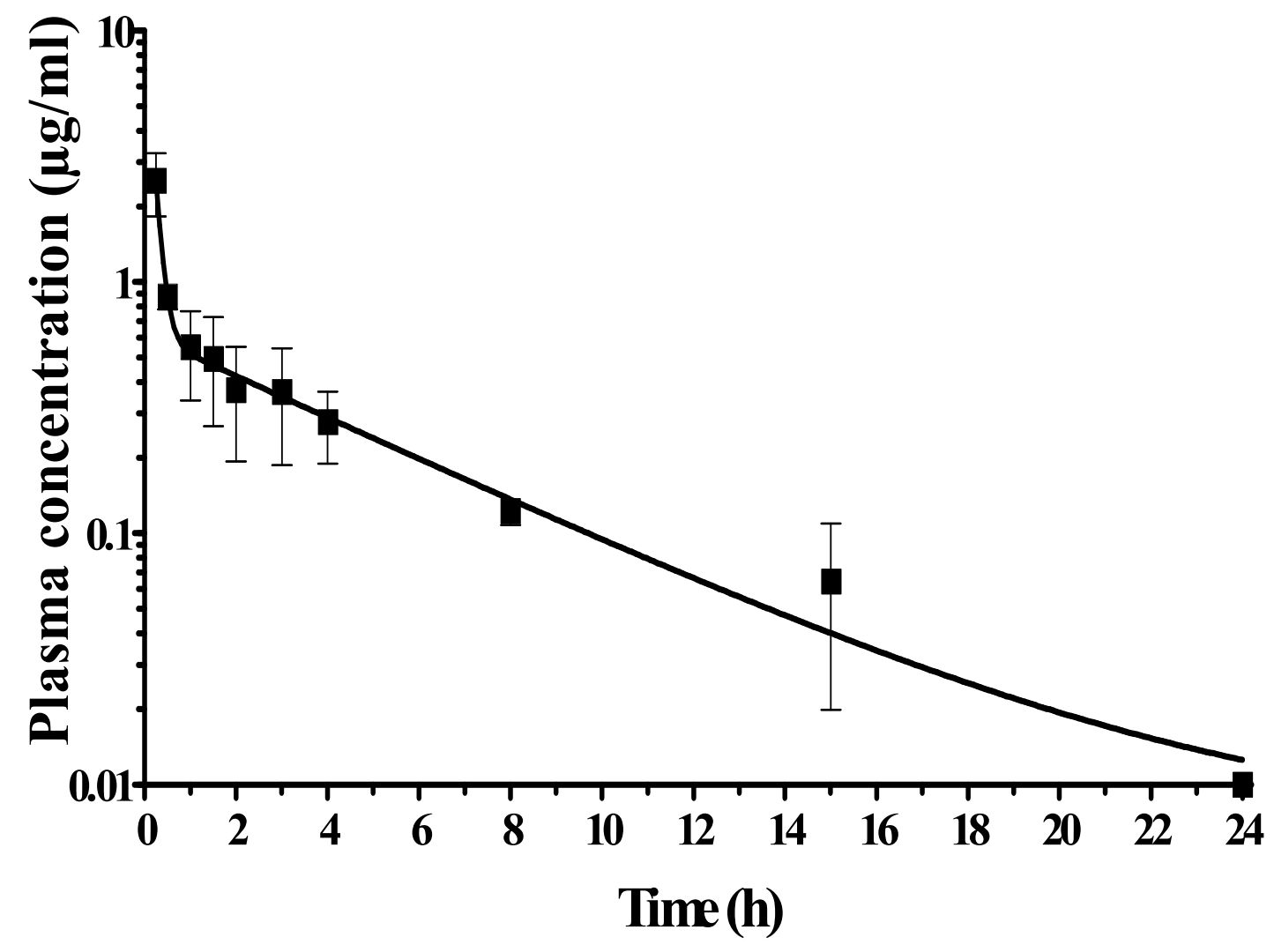

Figure 3, Touil et al. 


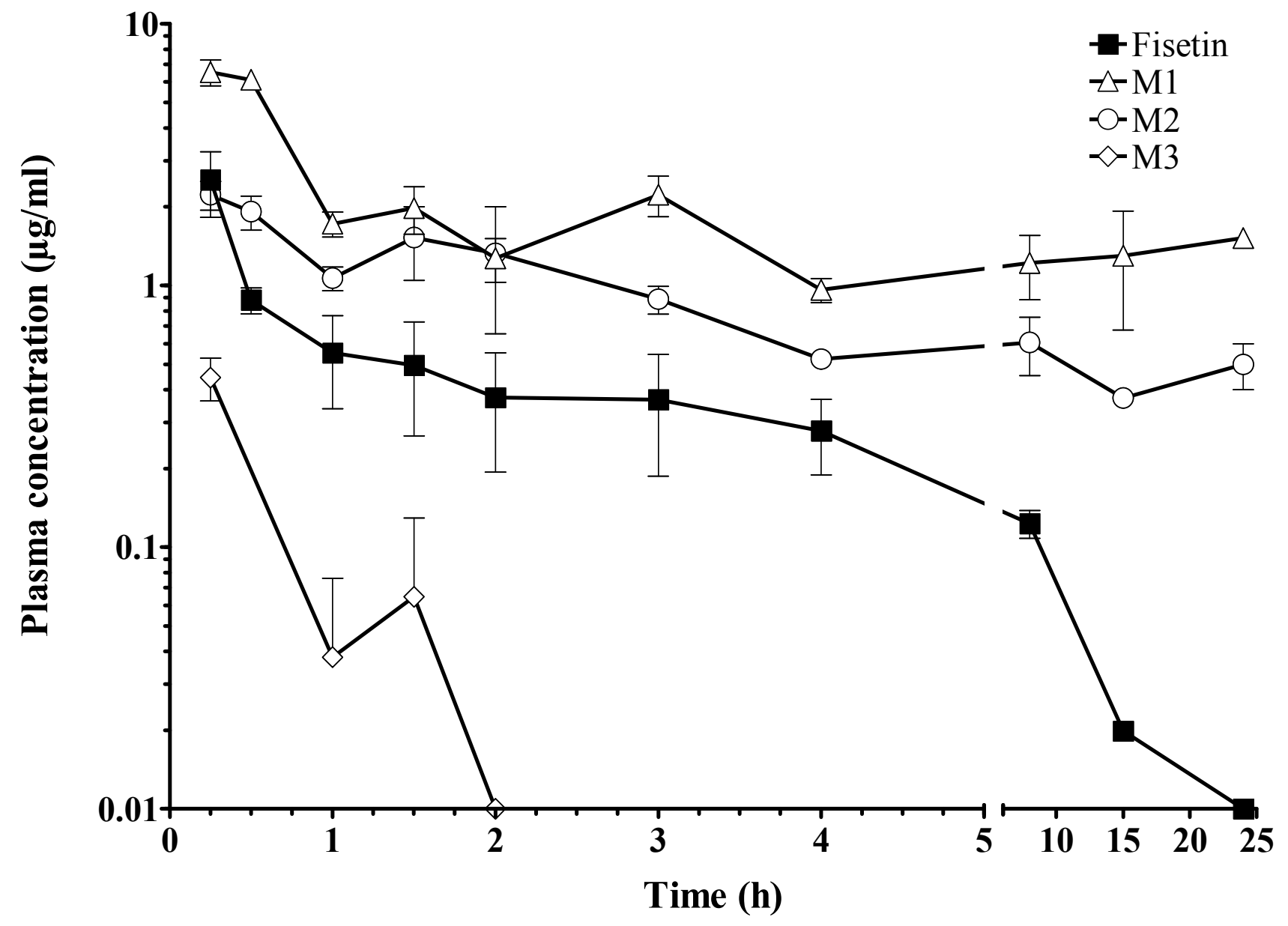

Figure 4, Touil et al. 


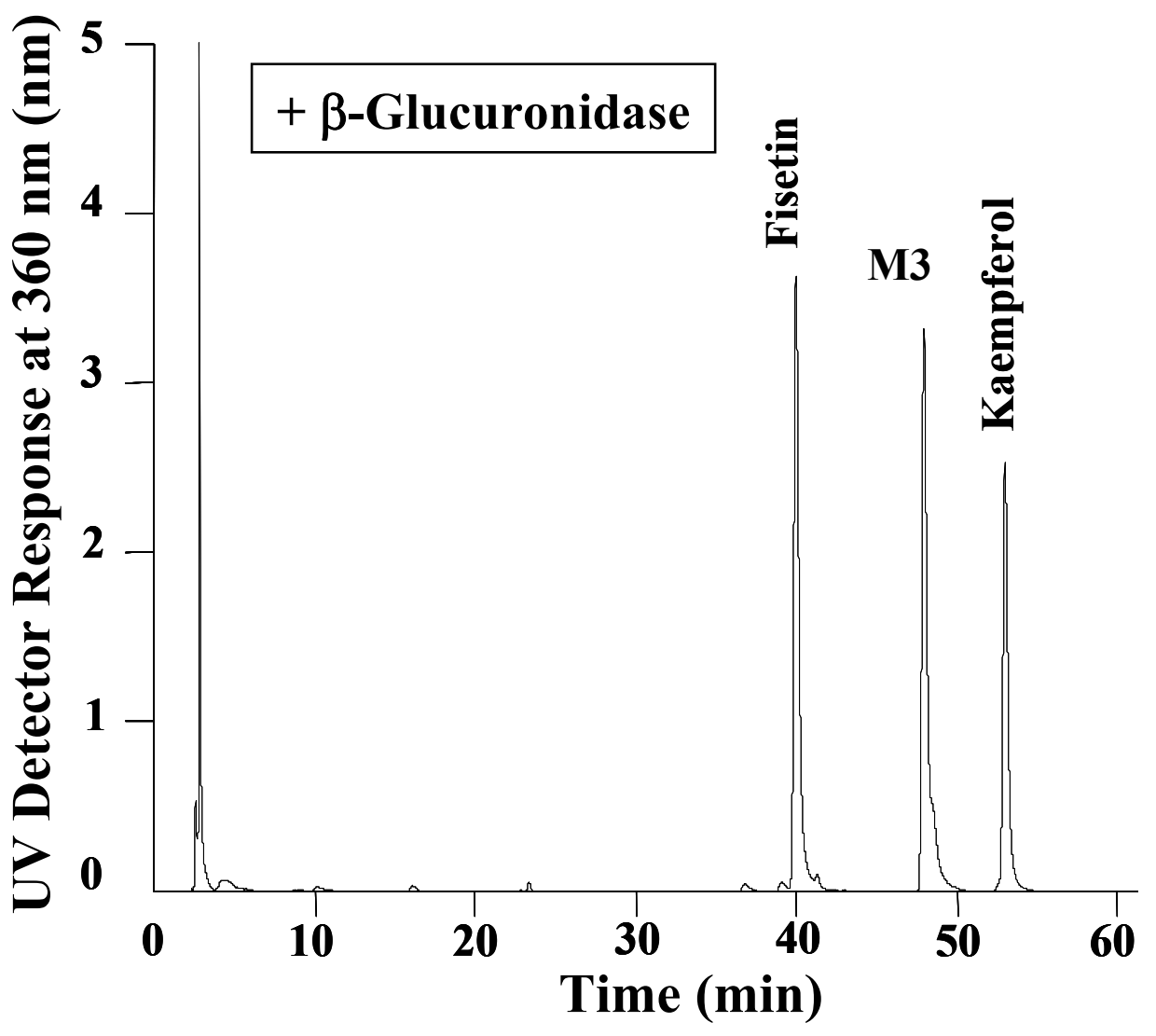

Figure 5, Touil et al. 

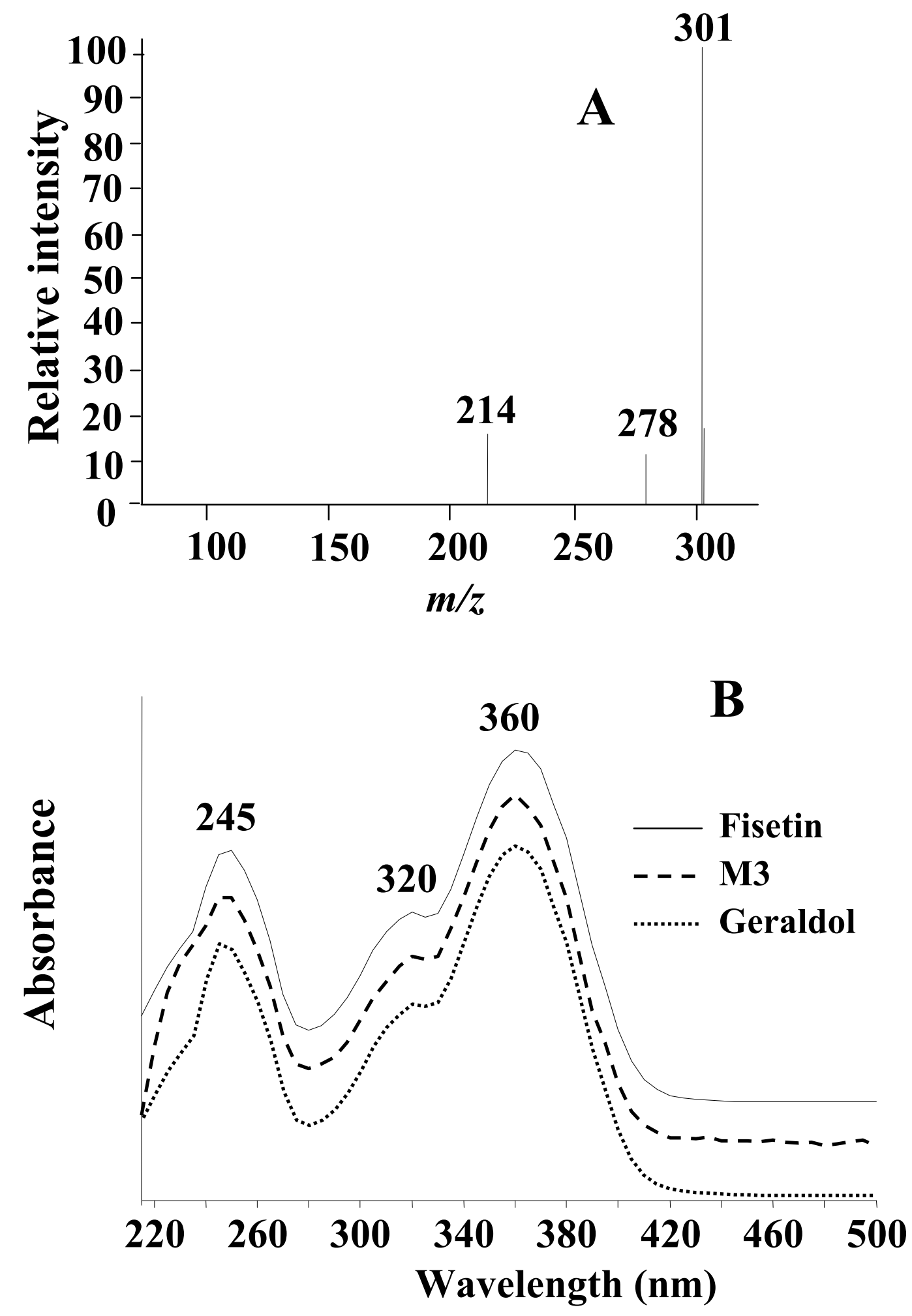

Figure 6, Touil et al. 

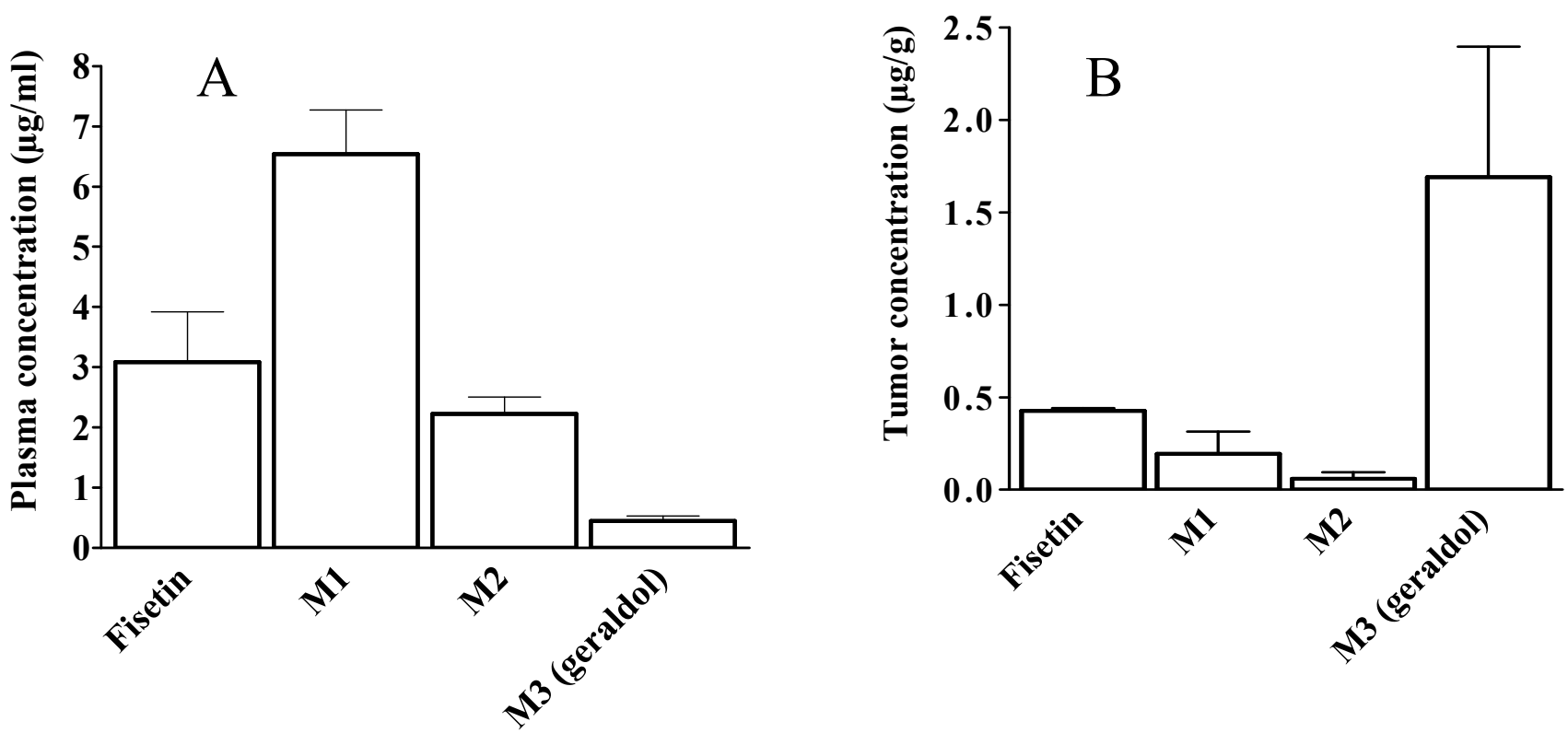

Figure 7, Touil et al. 


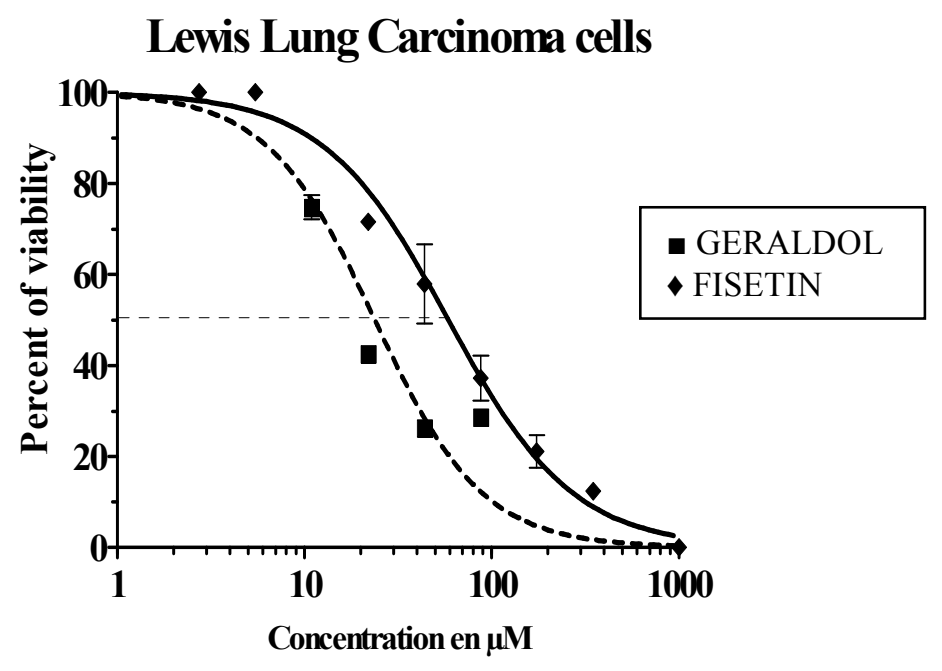

Eahy 926 endothelial cells
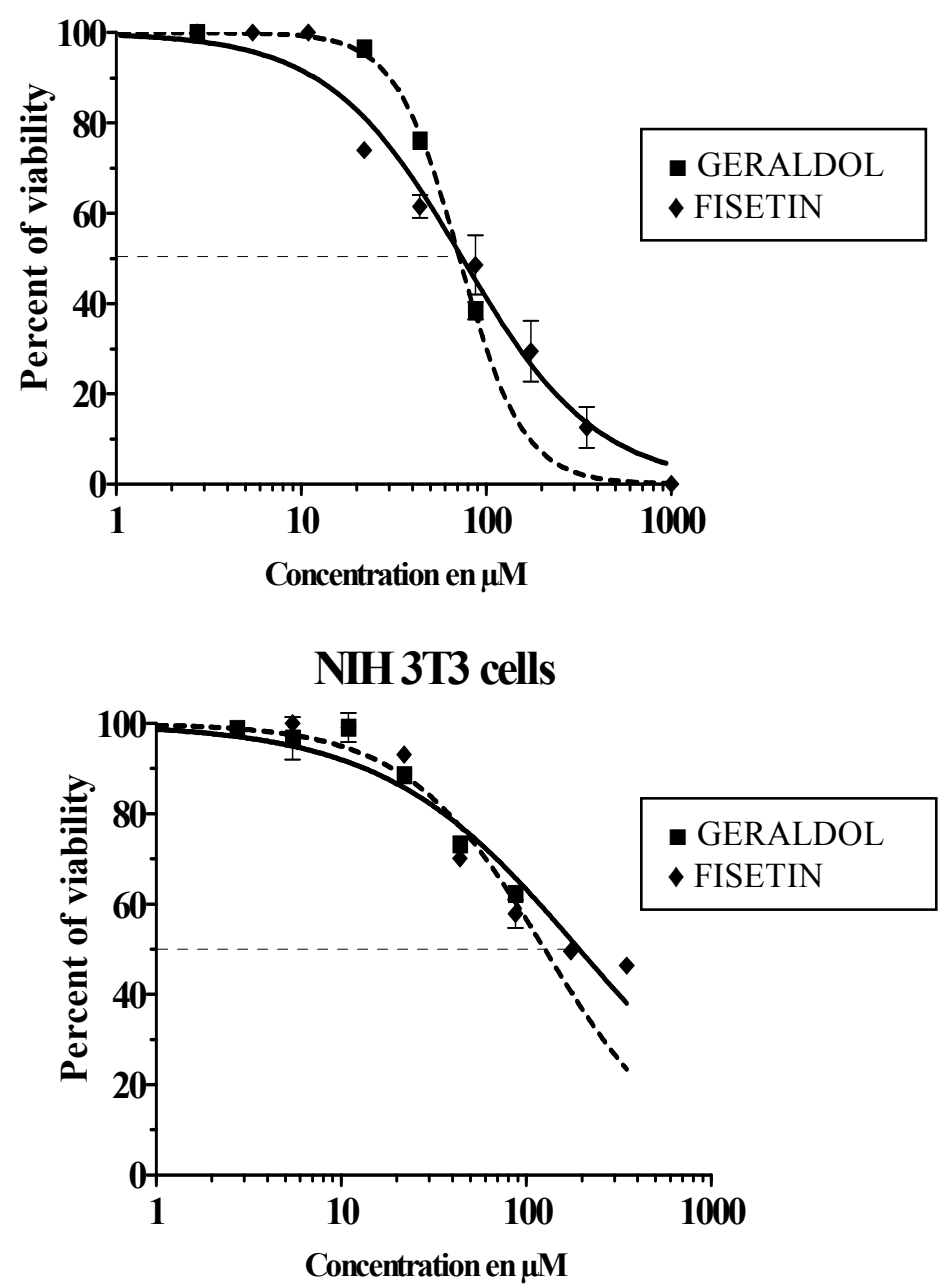

Figure 8, Touil et al. 


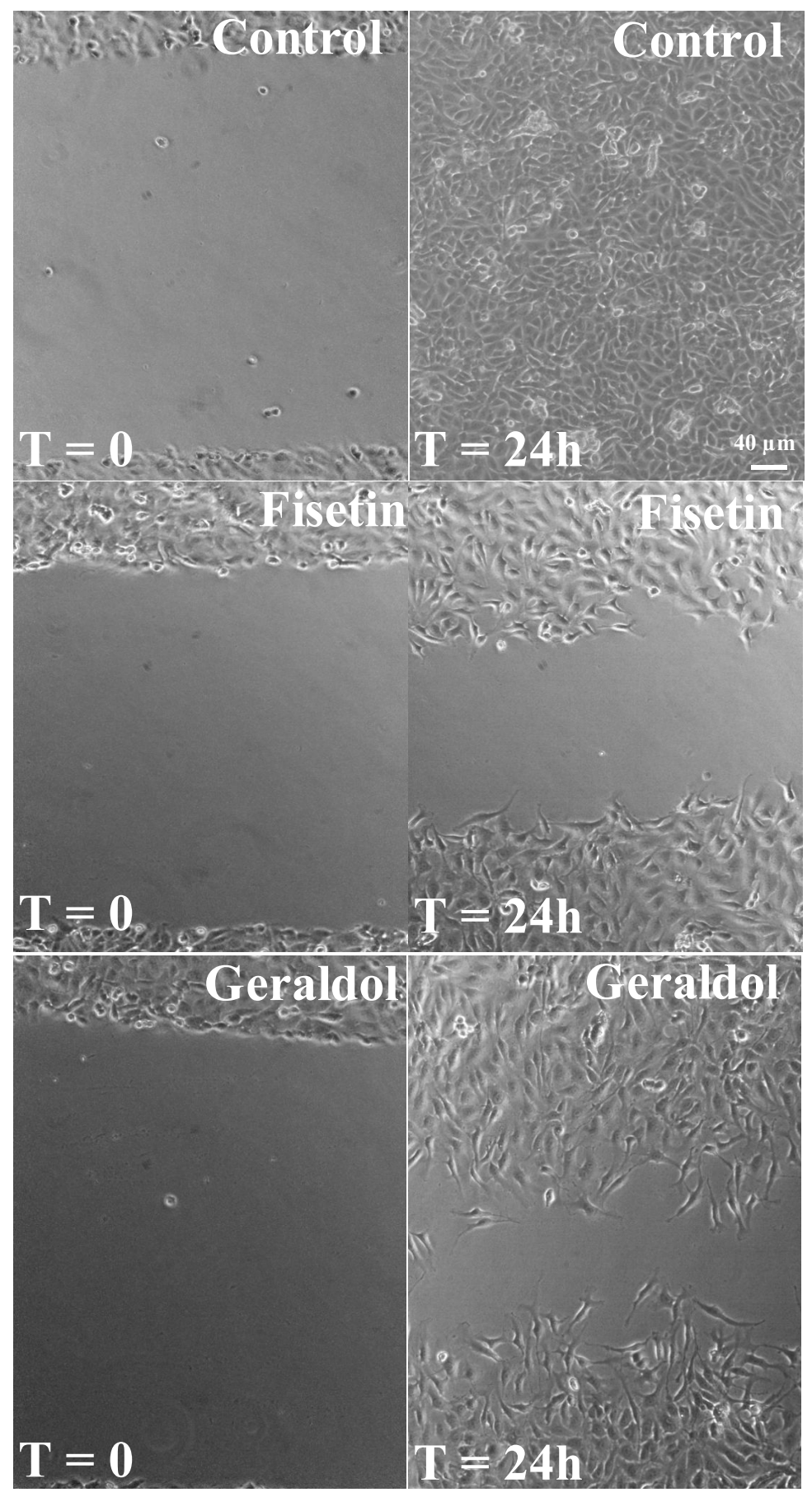

Figure 9, Touil et al. 


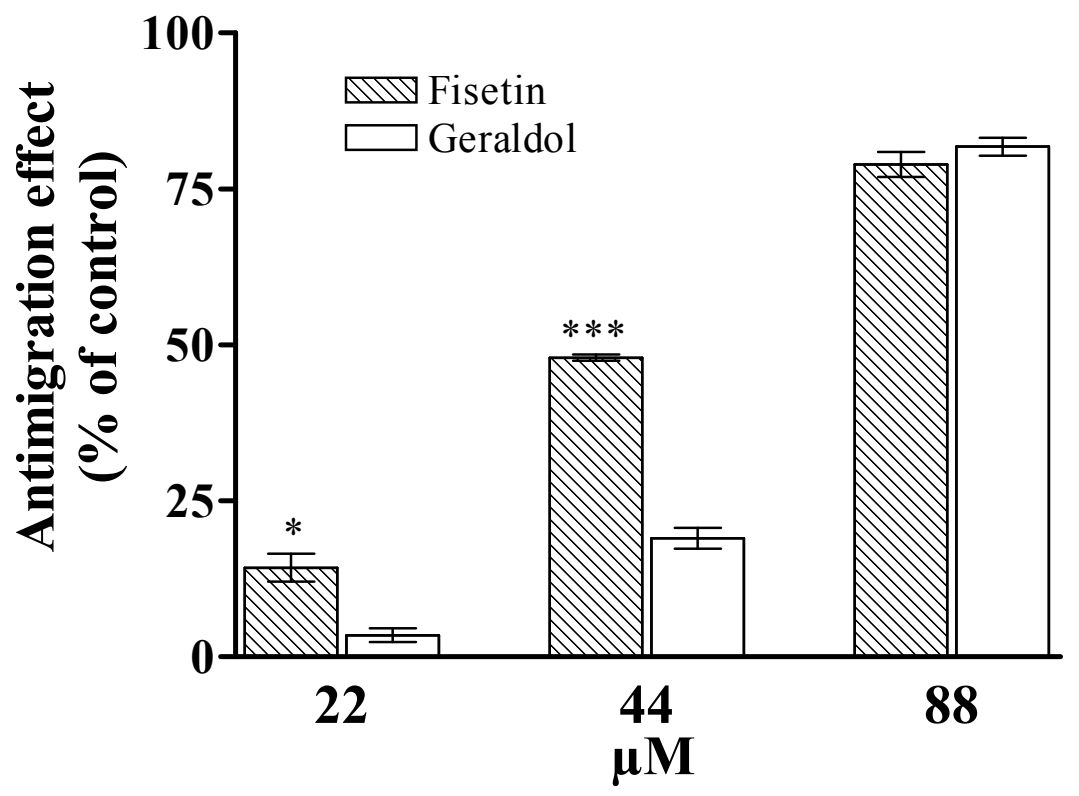

Figure 10, Touil et al. 